\title{
Improving methodology of automobile operating companies activities simulation modeling
}

\author{
Mavluda Irisbekova* \\ Tashkent State Transport University, Tashkent, Uzbekistan
}

\begin{abstract}
This article is devoted to the study of the use of mathematical hardware in the efficient organization of the system of servicing motor vehicles. Herewith, simulation modeling methods enable obtaining information about the state of the system analyzed with the application of its programmed model. This information is then used in the design of system management. In addition, proposals have been developed to improve the car maintenance process within the framework of generating random values corresponding to the distribution of probabilities by type of service over the period of entry into the car maintenance system.
\end{abstract}

\section{Introduction}

Motor vehicles system is rapidly developing from year to year in terms of quality and quantity. Currently, the annual growth of the global car fleet constitutes 12-14 million units, with a total number of over 550 million units. Four out of every five motor vehicles in the global car fleet are motor cars [21].

The high level of society provision with cars requires the solution of such an essential problem as maintenance and repair of motor vehicles. Therefore, the methodology used in formulating the performance of the transport logistics services market and assessing its quality ensures quality and integrity [19].

It should be noted that the complexity of vehicle design, lack of the required technical equipment and skills of motor car owners, lack of time, the need for constant maintenance and repair of the car resulted in the emergence and development of the car service system. In this regard, activity-based microscopic models are more efficient for simulating transport [3].

Meeting the requirements for a motor vehicle is provided in the following two main areas:

1. Through the system of car service companies;

2. In reliance upon the principle of "self-service" (by the car owner himself or with the help of other persons).

An increase in the number of vehicle fleets increases demand for workers in the field of maintenance and repair services. Meeting the population's demand for these services will be achieved by raising the volume of services provided and reducing the population's

*Corresponding author: m.irisbekova@mail.ru 
demand for car service. A decrease in demand for car service occurs due to the quality of maintenance and repair works and improving the reliability of the motor vehicle. Thus it is recommended to hold continuous search and implementation of solutions for modeling the company's activities using ARENA modeling software at the car service companies. Analysis of results will enable to optimize the experimental model for the efficient use of available resources [12].

In this regard, scholars have proposed the model of improving the logistics system of the car service network by optimizing the supply of spare parts by enhancing the number of workstations in each car service [11].

Herewith, from the above considerations of the scholars, it is clear that not all of the listed factors are directly related to the activities of the car service.

The demand for transportation of the population in private vehicles depends on the satisfaction of the demand for car maintenance and repair services, which enables to determine the location of car service companies in the system.

In compliance with the current conditions and objectives, it is necessary to undertake measures to reengineer the car service company, that is, to make radical changes using technology [17].

The car service system includes car service stations (CSS), gas stations, campsites, motels, car showrooms, spare parts and material warehouses, car parks, special repair shops, parking lots, garages, specialized service stations, companies engaged in repair and maintenance of individual parts, components, and assemblies of the vehicle, recovery of damaged vehicles, maintenance of individual vehicles and other companies [18].

The following factors make an impact on the growth of demand for car services in our country in recent years:

- decentralization of the national car fleet;

- change of ownership in motor vehicles;

- development of small and private business;

- development of long-distance and international transport;

- increased demand for service on highways and international roads;

- production, launch into the market of various new models of motor vehicles, etc.

The methodology of ergonomic analysis has been used to create a safe working environment at the car service station [10].

The services provided in this system have a comprehensive description and cover the entire process from the sale of the motor vehicle to its future performance.

\section{Methods}

The number and types of motor vehicles and the diversification of their maintenance create certain difficulties in managing the system. These difficulties arise due to the complexity of the relationship between the various elements of the system. It should be noted that a change in one of the elements in a system, in turn, causes alteration change in the overall results.

This enables to study of the complex of relationships using simulation modeling (SM) techniques to achieve the scheduled goal. The most common analytical, statistical, and simulation models focus on solving mathematical problems and optimizing systems [7].

Simulation modeling is an efficient tool in the research of real systems. Simulation modeling methods provide an opportunity to obtain information about the state of the analyzed system using its programmed model, and this information is then used in the design of system management. However, simulation modeling does not solve optimal 
problems but provides a technique for assessing the significance of the functional description of the modeling system.

To simplify the simulation modeling statement, we provide an analytical list of random numbers and apply them in our future activities (see Table 1).

The idea of contemporary advanced simulation modeling is similar to the Monte Carlo method, in which the selection of random numbers to form probable or accurate estimates of any quantity is important. Basic concepts of probabilities are considered in Markov processes and convex optimization [1].

The main difference between contemporary simulation modeling methods and the Monte Carlo method is that time is not a real factor in the Monte Carlo method; the values obtained are "still" static). Herewith the basic ideas for creating the Monte Carlo method, implementing it on a computer, and optimizing the simplest scheme are provided. Particular attention is paid to the basic algorithms for modeling random variables and vectors and the ways to reduce complexity [13].

Monte Carlo simulation is used to provide a shift between macroscopic and microscopic cases [2].

Table. 1. Approximate list of random numbers in the range $[0 ; 1]$

\begin{tabular}{|l|l|l|l|l|l|}
\hline 0.0589 & 0.3529 & 0.5869 & 0.3455 & 0.7900 & 0.6307 \\
\hline 0.6733 & 0.3646 & 0.1281 & 0.4871 & 0.7698 & 0.2346 \\
\hline 0.4799 & 0.7676 & 0.2867 & 0.8111 & 0.2871 & 0.4220 \\
\hline 0.9486 & 0.8931 & 0.8216 & 0.8912 & 0.9534 & 0.6991 \\
\hline 0.6139 & 0.3919 & 0.8261 & 0.4291 & 0.1394 & 0.9745 \\
\hline 0.5933 & 0.7876 & 0.3866 & 0.2302 & 0.9025 & 0.3428 \\
\hline 0.9341 & 0.5199 & 0.7125 & 0.5954 & 0.1605 & 0.6037 \\
\hline 0.1782 & 0.6358 & 0.2108 & 0.5423 & 0.3567 & 0.2569 \\
\hline 0.3473 & 0.7472 & 0.3575 & 0.4208 & 0.3070 & 0.0546 \\
\hline 0.5644 & 0.8954 & 0.2926 & 0.6975 & 0.5513 & 0.0305 \\
\hline
\end{tabular}

Since simulation modeling is also a random experiment, any result obtained is prone to experimental errors and, therefore, like any static experiment, relies on static test results. As a result of the generated simulation, it is possible to assess the adequacy of the model based on the Fisher criterion [15].

Modeling helps manufacturers make the right decisions, create a new company, as well as improve the process [4]. In this case, the task of modeling is to evaluate the description of the operations of the service system, for example, the average time or the average duration of the queue. The essence of modeling is based on using the capabilities of the mathematical apparatus of queuing theory in solving problems of arranging technological processes [8] (the author has used I OP88 analysis language).

Such descriptions of the public service system change their values when the customer's arrival or at the end of the service. In other cases, in terms of simulation modeling, there are no significant changes in the system. Basic modeling and simulation tools are used, and these tools are very important to support the system's daily operations. [9].

All simulation models reflect the situations in which discrete events are directly or indirectly queued: customers come to the service station, queue when necessary, and leave the system after service. In general, in a discrete event, any model consists of a network of interconnected queues, and under a discrete simulation model, the main event is the arrival and departure of customers. 


\section{Results and Discussion}

The following model represents the imitation model of car repair and maintenance in the service of Open Joint Stock Company "Avtotechkhizmat." The mathematical model is targeted to optimize multiple parameters and functions and formulate a complete set of efficient plans [6].

Based on the research conducted to create the simulation model, statistical data have been collected and processed. Herewith the activity in the maintenance service consists of nine queues (cases) corresponding to the four maintenance sections, and these events are shown in Table 1.

Table 2. Possible cases in rendering technical services to motor vehicles

\begin{tabular}{|c|l|}
\hline Cases & Type of repair and maintenance service \\
\hline $\mathrm{A}_{11}$ & $\begin{array}{l}\text { The motor vehicle comes to the Technical Service Station to have his } \\
\text { car repaired №2 and stands in queue №1. }\end{array}$ \\
\hline $\mathrm{A}_{21}$ & $\begin{array}{l}\text { The motor vehicle arrives at the Technical Service Station for engine } \\
\text { repair and maintenance and stands in queue №2. }\end{array}$ \\
\hline $\mathrm{A}_{31}$ & $\begin{array}{l}\text { The motor vehicle arrives at the Technical Service Station for bodywork } \\
\text { and stands in queue №3 }\end{array}$ \\
\hline $\mathrm{A}_{41}$ & $\begin{array}{l}\text { The motor vehicle arrives at the Technical Service Station to the Road } \\
\text { Maintenance Facility section and stands in queue №4. }\end{array}$ \\
\hline $\mathrm{B}_{11}$ & $\begin{array}{l}\text { The motor vehicle leaves section №2 of the Technical service and } \\
\text { stands in queues № 6, 7, or 8 to correct other faults if necessary. }\end{array}$ \\
\hline $\mathrm{B}_{21}$ & $\begin{array}{l}\text { The motor vehicle leaves the engine room and stands in queues № 5, 7, } \\
\text { or 8 to correct other faults as needed. }\end{array}$ \\
\hline $\mathrm{B}_{31}$ & $\begin{array}{l}\text { The motor vehicle leaves the body shop and, if necessary, stands in } \\
\text { queues 5, 6, or 8 to correct other faults. }\end{array}$ \\
\hline $\mathrm{B}_{41}$ & $\begin{array}{l}\text { The motor vehicle leaves the GM section and stands in queues № 5, 6, } \\
\text { or 8 to correct other faults as needed. }\end{array}$ \\
\hline $\mathrm{C}_{11}$ & $\begin{array}{l}\text { After case A11, the motor vehicle, having performed case B11 (with or } \\
\text { without), stands in queue №9, pays for the services rendered, and leaves } \\
\text { the Technical Service Station. }\end{array}$ \\
\hline $\mathrm{C}_{21}$ & $\begin{array}{l}\text { After case A21, the motor vehicle, having performed case B21 (with or } \\
\text { without), stands in queue №9, pays for the services rendered, and leaves } \\
\text { the Technical Service Station. }\end{array}$ \\
\hline $\mathrm{C}_{31}$ & $\begin{array}{l}\text { After case A31, the motor vehicle, having performed case B31 (with or } \\
\text { without), stands in queue №9, pays for the services rendered, and leaves } \\
\text { the Technical Service Station. }\end{array}$ \\
\hline $\mathrm{C}_{41}$ & $\begin{array}{l}\text { After case A41, the motor vehicle, having performed case B41 (with or } \\
\text { without), stands in queue №9, pays for the services rendered, and leaves } \\
\text { the Technical Service Station. }\end{array}$ \\
\hline
\end{tabular}

One of the key issues in simulation modeling is to determine the start time of each case. Cases related to the time of arrival in the system are determined by the time between the arrival of customers, and their departure is determined by the time of service [20]. The onset time of these cases can be precise or random. In the matter we are analyzing, the time that motor vehicles are in the system is random. Using analytics tools, the Aimsun software package enables a simulation of a transport model [8].

Herewith, a special procedure is used to generate the selected time value in the case range in the system, which corresponds to the given probability distribution. Simulated models of car service work designed to search for stable parameters of system operation are presented [14]. Theoretically, these results can be achieved based on quality improvement and services rendered [16]. 
Below we consider the following methods for generating random values $\left(t=t_{1}, t_{2}, \ldots . t_{n}\right)$ of time probabilities corresponding to a given distribution in the customer arrival interval:

* inverse function method;

* "convolution" method;

* sampling method.

Theoretically, these results can be achieved based on quality improvement and services provided [16].

The inverse function method is mainly used in continuous distribution, in which distribution functions tend to be analytic. The "convolution" and sampling methods are more universal and are used in complex situations, such as generating random numbers that correspond to a normal distribution or a Poisson distribution. According to the inverse function method (IFM), let it be necessary to form $x$ value of a random variable $y$ with probability density $f(x)$. According to the inverse function method, first, for all values of $\mathrm{x}$, all $F(x)=P\{y \leq x\}$, where $0 \leq F(x) \leq 1$, the distribution function is found.

$\mathrm{R}$ is a random number formed from a flat distribution in the range $[0 ; 1]$, let $\mathrm{F}^{1}$ be the inverse of $\mathrm{F}$. Two-stage factors are performed under the inverse function method:

Step 1: Generating analytical number $\mathrm{R}$ in the range $[0 ; 1]$;

Step 2: Calculating an unknown random number $\mathrm{x}=\mathrm{F}^{1}(\mathrm{R})$.

We analyze this method according to the issue under consideration. The intervals of the arrival of motor vehicles for maintenance - $t$ are distributed according to the exponential law, and the mathematical expectation is $M(t)=1 / \lambda$, i.e., the probability density can be demonstrated by the following formula:

$$
f(t)=\lambda e^{-\lambda t}
$$

It is necessary to determine the random value of time. Using the distribution function

$$
F(t)=\int_{0}^{t} \lambda e^{-\lambda x} d x=1-e^{-\lambda t}
$$

we determine time $t$ :

$$
e^{-\lambda t}=1-F(t)
$$

Finding the logarithm of two parts of (2.), we get the following: $-\lambda \mathrm{e}=\ln (1-$ $F(t))$.

Here:

$$
t=-\frac{1}{\lambda} \ln (1-F(t))
$$

If $\mathrm{R}=\mathrm{F}(\mathrm{t})$ is a random number in the range $[0 ; 1]$, then to determine the time of arrival of motor vehicles to the voluntary car service, we get the following equation:

$$
t=-\frac{1}{\lambda} \ln (1-R)
$$

In simulation modeling, let events occur after time $t$. In this case, for example, if $\lambda=5$ motor vehicles per hour come to the service center and when $\mathrm{R}=0.8$, the time between the arrival of cars for maintenance is calculated as follows:

$$
t_{1}=-\frac{1}{5} \ln (1-0,8)=0,32 \text { hour }=19,3 \text { minutes }
$$

"Convolution" method. The essence of this method is that an unknown random variable is expressed in the form of a sum of other random variables so that it is easy for them to generate random values. Among such distributions, the Erlang and Poisson distributions are 
a clear example, and they can be generated from an exponential function. According to Erlang law, the distribution of $m$ parameter A random variable ( $m$ - integer number) with distribution according to Erlang law is determined as the sum of $m$ independent random values, each of which has an exponential distribution of parameter 1. If ym parameter is a random quantity distributed by Erlang law, then:

$$
\mathrm{y}=y=y_{1}+y_{2}+\cdots+y_{m}
$$

here: $y_{i}(i=\overline{1, m})$ are independent exponentially distributed random quantities, which probability density is calculated from the following formula:

$$
f\left(y_{i}\right)=\lambda e^{-\lambda y_{i}}
$$

Since (5) is a random number in the range $\mathrm{R}[0 ; 1],(1-R)$ is also a random number in this range. Therefore, $(1-R)$ in $(2.31)$ can be replaced by $R$. In that case, the random magnitude of $y_{\mathrm{i}}$ is determined by the following formula:

$$
y_{i}=-\frac{1}{\lambda} \ln R_{i}
$$

Thus, the value of the random magnitude of Erlang with parameter $m$ can be calculated as follows:

$$
y=-\frac{1}{\lambda} \ln \left(R_{1} R_{2} \ldots R_{m}\right)
$$

Distribution according to the Poisson method. Suppose the time between certain cases is a random variable distributed by the exponential law. In that case, the distribution of the number of cases per unit time is according to Poisson law. This is used to generate random values distributed in compliance with Poisson law.

Let the problem under consideration follow the Poisson distribution, and let the average number of events per unit time be equal to $\lambda$. In that case, the time between events is a random quantity with an exponential distribution. This implies that for $n$ cases to occur in $t$ units of time:

$n$ case time must be met $n \leq t \leq n+t$ case time.

This condition can also be written as follows:

$$
t_{1}+t_{2}+\ldots+t_{n} \leq t \leq t_{1}+t_{2}+\ldots+t_{n+1}, n>0, \quad 0 \leq t \leq t_{1}, n=0
$$

Here $t_{i}$ is a random variable with an average value of $1 / \lambda$, subject to the exponential distribution. According to (12.):

$$
-\frac{1}{\lambda} \ln \left(R_{1} R_{2} \ldots R_{n}\right) \leq t \leq-\frac{1}{\lambda} \ln \left(R_{1} R_{2} \ldots R_{n+1}\right), \quad n>0(11)
$$

From (10):

$$
R_{1} R_{2} \ldots R_{n} \geq e^{-\lambda t} \geq R_{1} R_{2} \ldots R_{n+1}, \quad n>0 .
$$

Let $\lambda=4$ (i.e., an average of 4 motor vehicles arrive at the service station) and $t=0.5$ hours to determine a random value corresponding to the distribution according to Poisson. 
having calculated $e^{-\lambda t}$, we get the result of 0,1353 .

from the interval $[0 ; 1]$ we create a random number (here we get the first number given in the first table, i.e., we use R1 $=0.0589$ ). Since this number is less than the value of $e^{-\lambda t}$, it is $\mathrm{n}=0$, i.e., at the analyzed period of time, no motor vehicles have arrived at the maintenance service.

Normal distribution. According to the central limit theorem, the sum of $n$ randomly distributed random quantities tends to normal size when $n$ is infinitely magnified. This theorem is applied in generating random values corresponding to a normal distribution where the mathematical expectation $\lambda$ and the standard deviation $\sigma$ can be.

$\mathrm{x}$ is the sum of $\mathrm{n}$ randomly distributed random variables in the range $[0 ; 1]$, let be an asymmetric normal quantity with mean value $\mathrm{n} / 2$ and dispersion $\mathrm{n} / 12$. Hence, a random variable subject to a normal distribution $(\mathrm{N}(\lambda, \sigma))$ can be formulated from a random quantity $x$ by the following formula:

$$
y=\lambda+\sigma\left(\frac{x-\frac{n}{2}}{\sqrt{\frac{n}{12}}}\right)
$$

If we accept as $n=12$.

Thus, to generate the values of a random variable of normal distribution, it is necessary to formulate 12 randomly distributed random numbers $[0 ; 1]$, calculate their sum, and use the formula (3.39), knowing the mathematical expectation $\lambda$ and standard deviation $\sigma$. For example, to generate random numbers that are subject to the normal distribution of $N$ (10.2), we compute the sum of twelve random numbers from Table 1 to receive $x=6.1094$. Thus, $y=10+2(6,1094-6)=10,2188$.

Sampling method. This method is designed to generate values of random variables with complex functional probability densities, which cannot be supported by inverse function and "birth" methods. The essence of this method is to replace the complex probability $f(x)$ with the probability density $f(x)$, which is more convenient from an analytical point of view.

\section{Conclusions}

Within the framework of the problem considered, there is proposed the method of simulation modeling which enables to enhance the level of diversification of maintenance of motor vehicles in the efficient organization of the system of servicing motor vehicles with the account of the number and types of vehicles. In this research paper, the time interval between customer arrival is a random variable; the mathematical expectation varies according to the exponential law, the service time is evenly distributed in this interval. In addition, the time interval of the arrival of vehicles on the site and the time of servicing the vehicles are determined. Furthermore, in the process of research, simulation models of work of other sections of the car service are evaluated according to the fact that the quality of work on these sections is assessed by the long queues of cars, which shows the need to increase the number of masters in these sections.

\section{References}

1. Reuven Y. Rubinstein, Dirk P. Kroese. Simulation and the Monte Carlo Method, Third Edition. First published: November, 21 (2016).

2. Adam Torok. Monte-Carlo simulation of road transport emission, Budapest University of Technology and Economics, Department of Transport Technology and Economics, Hungary Received: July 24,2014; accepted: September 19, (2014). 
3. Jiri Horak 1, Jan Tesla 1, David Fojtik 2 and Vit Vozenilek, Article Modelling Public Transport Accessibility with Monte Carlo Stochastic Simulations: A Case Study of Ostrava

4. Muhammet Enes Akpınar 1, Sadık Alper Yıldızel 2, Yiğit Karabulut 3, Erkan Doğan 2 Simulation Optimization for Transportation System: A Real Case Application, Manisa Celal Bayar University, Industrial Engineering Dept., Manisa, Turkey.

5. Tarov A.G., Gunba V.S. Application of simulation modeling in solving problems in the system of road transport repair.

6. Rojko O. N. Khomenko V. V. Transformation of the national market of logistics services in the digital economy of the Kazan National Research Technical University (KAI) named after A.N. Tupolev.

7. Tyan K.L. Analytical, statistical and simulation models. (2020).

8. Kuftinova N.G. Development of a regional transport model using simulation modeling using AIMSUN.

9. Ana Luísa, Ferreira Andrade Ramos, José Vasconcelos Ferreira, Jaume Barcelo. Modeling \& Simulation for Intelligent Transportation Systems. January (2012).

10. Popova K. Makarova I. Application of simulation models for perfection autoservice processes. DOI: 10.12737/18006. March (2016).

11. Ksenia Shubenkova, ${ }^{\text {a }}$ VadimMavrin, ${ }^{a}$ Kuanysh Abeshev ${ }^{c}$, Improvement of Automotive Service Management by Means of Computer Simulation

12. I.Radulescu, A C Tociu ${ }^{1}$ and A V Radulescu. Modeling and simulating the activities in an automobile repair shop using ARENA software - part 1.

13. Voitishek A.V. Lectures on numerical methods of Monte Carlo. Novosibirsk State University.

14. Timchenko V.S. The structure of car service imitation modeling. Institute of Transport Problems N.S. Solomenko Russian Academy of Sciences, Russia.

15. Bugrimov Vitaly Alekseevich, Kondratyev Aleksey Vasilievich, Sarbaev Vladimir Ivanovich, Assessment of the adequacy of the simulation model of the management system of a car service company. Issue: 2(61), 2018 pp 124-131.

16. Chichkina V. D. Experience of restructuring a trade and service company under conditions of uncertainty, Chichkina V. D. // Russian Entrepreneurship. 2004.(3). Pp 68-70. (2004)

17. Chichkina, V. D. Methods for conducting a survey and modeling business processes of an enterprise, Chichkina V. D. Russian Entrepreneurship, 5. pp 54-55. rus. - RUMARS-ropr04_000_005_0054_1. - Perm State Regional Universal Library named after A. M. Gorkiy. - N 5. - C. 54-55. - ropr04_000_005_0054_1, 5, 54-55.( 2004).

18. Begele Sioro. Algorithm for the implementation of the model for the placement of car service centers on the example of the central military repair enterprise in Markala in Mali [Text], Begele Sioro // Economic Sciences. - 2007. (4). - p. 98102, RUMARS-ekna07_000_004_0098_1. - Tver Regional Universal Scientific Library named after A. M. Gorky. - ekna07_000_004_0098_1 (2007).

19. Irisbekova M.N. Methodology of organization and quality assessment of transport and logistics services market. International Journal of Psychosocial Rehabilitation, 24, (04), (2020)

20. Mamayev Ye.A., Kovaleva N.A., Khashheyev A.T. and Mulenko O.V. The social and economic factors of the city transport development. www.wto.org - World Trade Organization 